\title{
Protection of Human Umbilical Vein Endothelial Cells against Oxidative Stress by MicroRNA-210
}

\author{
Tianyi Li, Xianjing Song, Jichang Zhang, Lei Zhao, Yongfeng Shi, Zhibo Li, Jia Liu, \\ Ning Liu, Youyou Yan, Yanlong Xiao, Xin Tian, Wei Sun, Yinuo Guan, and Bin Liu \\ Department of Cardiology, The Second Hospital of Jilin University, Changchun, Jilin, China \\ Correspondence should be addressed to Bin Liu; liubin3333@vip.sina.com
}

Received 4 November 2016; Revised 12 January 2017; Accepted 9 February 2017; Published 7 March 2017

Academic Editor: Jaideep Banerjee

Copyright (c) 2017 Tianyi Li et al. This is an open access article distributed under the Creative Commons Attribution License, which permits unrestricted use, distribution, and reproduction in any medium, provided the original work is properly cited.

\begin{abstract}
Oxidative stress induces endothelial cell apoptosis and promotes atherosclerosis development. MicroRNA-210 (miR-210) is linked with apoptosis in different cell types. This study aimed to investigate the role of miR-210 in human umbilical vein endothelial cells (HUVECs) under oxidative stress and to determine the underlying mechanism. HUVECs were treated with different concentrations of hydrogen peroxide $\left(\mathrm{H}_{2} \mathrm{O}_{2}\right)$, and cell viability was evaluated using the 3-(4,5-dimethylthiazol-2-yl)-2,5-diphenyltetrazolium bromide assay and ATP assay. To evaluate the role of miR-210 in $\mathrm{H}_{2} \mathrm{O}_{2}$-mediated apoptosis, gain-and-loss-of-function approaches were used, and the effects on apoptosis and reactive oxygen species (ROS) level were assayed using flow cytometry. Moreover, miR210 expression was detected by quantitative reverse transcriptase polymerase chain reaction (qRT-PCR), and expression of the following apoptosis-related genes was assessed by qRT-PCR and Western blot at the RNA and protein level, respectively: caspase8 -associated protein 2 (CASP8AP2), caspase-8, and caspase-3. The results showed that $\mathrm{H}_{2} \mathrm{O}_{2}$ induced apoptosis in HUVECs in a dose-dependent manner and increased miR-210 expression. Overexpression of miR-210 inhibited apoptosis and reduced ROS level in HUVECs treated with $\mathrm{H}_{2} \mathrm{O}_{2}$. Furthermore, miR-210 downregulated CASP8AP2 and related downstream caspases at protein level. Thus, under oxidative stress, miR-210 has a prosurvival and antiapoptotic effect on HUVECs by reducing ROS generation and downregulating the CASP8AP2 pathway.
\end{abstract}

\section{Introduction}

Atherosclerosis is the leading cause of coronary heart disease, with high mortality and morbidity rates [1]. Under oxidative stress, excessive reactive oxygen species- (ROS-) induced endothelial cell apoptosis plays a crucial role in atherosclerosis development [2]. Therefore, reduction of endothelial apoptosis is vital in atherosclerosis prevention.

The association of microRNAs (miRNAs), which are involved closely in various cell processes through posttranscriptional downregulation of their target mRNAs, with apoptosis has drawn much attention [3-6]. In particular, expression of miRNA-210 (miR-210) has been considered a general response to hypoxia [7], and miR-210 has been reported to be participated in various cellular processes, including cell cycle arrest [8], angiogenesis [6], and cell survival [5] in various cell types, including endothelial cells [6]. Besides hypoxia, miR-210 is involved in oxidative stressinduced injury. Our previous study has revealed that miR-210 protects cardiomyoblasts against apoptosis under oxidative stress [9]. However, the role of miR-210 in cell apoptosis apparently varies with cell types and stimuli [10-13]. It has been reported that miR-210 protects cardiomyocytes against apoptosis under hypoxic conditions [10] and protects stem cells against oxidative stress [11]. However, some studies identified miR-210 as a proapoptotic component in human pulmonary artery epithelial cells [12] and in a human lung cancer cell line [13]. Therefore, the role of miR-210 in apoptosis in different cell types and under different conditions needs further investigation.

Some studies have indicated that miR-210 exerts antiapoptosis action by downregulating caspase-8-associated protein 2 (CASP8AP2) in stem cells under hypoxic conditions [5]. CASP8AP2 (or FLICE-associated huge protein), a 1,962-amino acid-long protein, takes part in several cellular processes, such as mRNA processing, cell cycle, apoptosis, and transcriptional control [14]. CASP8AP2 was identified 
as a proapoptosis member that acts via binding the death effector domains of procaspase- 8 , which activates caspase8 and its downstream caspases, including caspase-3, thereby participating in the extrinsic apoptosis pathway mediated by CD95 $[15,16]$.

However, the effect of miR-210 on endothelial cells under oxidative stress remains unclear. In this study, we investigated the effects of miR-210 on apoptosis and the underlying mechanism in human umbilical vein endothelial cells (HUVECs) treated with hydrogen peroxide $\left(\mathrm{H}_{2} \mathrm{O}_{2}\right)$, which has been commonly used to induce oxidative stress in in vitro models [17]. We found that miR-210 protected HUVECs against oxidative stress by reducing ROS generation and downregulating the CASP8AP2 pathway.

\section{Materials and Methods}

2.1. Cell Culture. HUVECs were obtained from the Department of Cardiology of The Second Hospital of Jilin University and cultured in a humidified incubator at $5 \% \mathrm{CO}_{2}$ and $37^{\circ} \mathrm{C}$. The complete growth medium for this cell line consisted of the vascular cell basal medium (ATCC, USA) with the endothelial cell growth kit-BBE (ATCC, USA) and contained the following components: $2 \%$ fetal bovine serum, $0.2 \%$ bovine brain extract, $10 \mathrm{mmol} / \mathrm{L}$ L-glutamine, $1 \mu \mathrm{g} / \mathrm{mL}$ hydrocortisone hemisuccinate, $5 \mathrm{ng} / \mathrm{mL}$ rhEGF, $50 \mu \mathrm{g} / \mathrm{mL}$ ascorbic acid, and 0.75 units/mL heparin sulfate.

2.2. Lentivirus Infection of HUVECs. A replication-deficient lentivirus was purchased from Sangon Biotech (Shanghai, China), encoding the human miR-210 precursor (pre-210), miR-210 inhibitor (anti-miR-210), or miR-scramble (miR-Scr, without miR-210 as a control) labeled with green fluorescent protein. $5 \mu \mathrm{L}$ of lentiviral vectors was added per well for transduction of HUVECs in 6 -well plates $\left(1 \times 10^{5}\right.$ cells/well $)$ for $12 \mathrm{~h}$. Fresh complete growth medium was subsequently added to replace the medium. To eliminate nontransduced cells, puromycin (Sigma-Aldrich, USA) was added to the medium at a final concentration of $4 \mu \mathrm{g} / \mathrm{mL}$ [18], and the medium was incubated for at least $72 \mathrm{~h}$. The transduced cells were then stained with DAPI and observed with a fluorescence microscope. The Image J software was used to quantitate the transduction efficiency.

2.3. DAPI Staining. After transduction with the lentivirus, cells were stained with DAPI to visualize the nucleus. Cells were cultured in a 6 -well plate and fixed in $4 \%$ paraformaldehyde for $25 \mathrm{~min}$ at room temperature $\left(25^{\circ} \mathrm{C}\right)$. Subsequently, cells were incubated with DAPI for $10 \mathrm{~min}$ and washed with PBS thrice.

2.4. Transfection. HUVECs were transfected in 6-well plates using Lipofectamine 2000 Reagent (Invitrogen, Carlsbad, CA, USA) according to the manufacturer's instructions. HUVECs were transfected with miR-210 mimics, miR-210 inhibitor, or negative control (NC) (GenePharma, Shanghai, China) at approximately $80 \%$ confluence.
2.5. 3-(4,5-Dimethylthiazol-2-yl)-2,5-diphenyltetrazolium Bromide (MTT) Detection. MTT detection was used to evaluate the viability of HUVECs treated with different concentrations of $\mathrm{H}_{2} \mathrm{O}_{2}$ and the effect of miR-210 on cell viability. Cells in a 96-well plate $\left(1 \times 10^{4}\right.$ cells/well $)$ were treated with different concentrations of $\mathrm{H}_{2} \mathrm{O}_{2}(0,0.1,0.2,0.5,1.0$, 1.5 , and $2.0 \mathrm{mmol} / \mathrm{L}$ ) for $24 \mathrm{~h}$. MTT (Biosharp, China) was added to each well, and the wells were incubated for $4 \mathrm{~h}$ at $37^{\circ} \mathrm{C}$. Subsequently, the medium was removed, and dimethyl sulfoxide (Sigma-Aldrich, USA) was added (150 $\mu \mathrm{L} /$ well) to solubilize the formazan crystals. Optical density was measured at $570 \mathrm{~nm}$ with a Varioskan Flash microplate reader (Thermo Scientific, USA), and cell viability was calculated as a percentage of the control optical density.

2.6. ATP Assay. To further evaluate cell viability, a luminescent ATP assay kit, CellTiter-Glo ${ }^{\circledR}$ Luminescent Cell Viability Assay (Promega, USA), was employed. Cells were treated with different concentrations of $\mathrm{H}_{2} \mathrm{O}_{2}(0,0.1,0.2,0.5,1.0$, 1.5 , and $2.0 \mathrm{mmol} / \mathrm{L})$ for $24 \mathrm{~h}$ in a white 96 -well plate $(1 \times$ $10^{4}$ cells/well). After the treatment, $100 \mu \mathrm{L}$ of CellTiter-Glo Reagent was added per well. The luminescence was then detected with a Varioskan Flash microplate reader (Thermo Scientific, USA). Cell viability was calculated as a percentage normalized to the control group.

2.7. Flow Cytometry. To detect apoptosis and determine ROS level of HUVECs treated with different concentrations of $\mathrm{H}_{2} \mathrm{O}_{2}$ and to assess the effect of miR-210, flow cytometry experiments were performed with the FACSCalibur system (BD Biosciences, USA). After treatment with different concentrations of $\mathrm{H}_{2} \mathrm{O}_{2}(0,0.5$, and $1.0 \mathrm{mmol} / \mathrm{L}), \mathrm{PE}$ Annexin $\mathrm{V}$ Apoptosis Detection kit I (BD Biosciences, USA) was used following the protocol for apoptosis detection. After transfection with miR-210 mimics, miR-210 inhibitor, or negative control, cells were dealt with $\mathrm{H}_{2} \mathrm{O}_{2}(0.5 \mathrm{mmol} / \mathrm{L})$. A Reactive Oxygen Species Assay Kit (Beyotime, China) was used following the protocol for ROS detection.

2.8. Quantitative PCR. Total RNA was extracted using Eastep $^{\circledR}$ Super Total RNA Extraction Kit (Promega, USA) following the protocol. The quality of the extracted RNA was evaluated with a NanoDrop 2000 Spectrophotometer (Thermo Scientific, USA). To detect miR-210 expression levels, RNA was reverse-transcribed into cDNA by using the miRcute miRNA First-Strand cDNA Synthesis Kit (TIANGEN Biotech, China) according to the protocol. To determine expression profiles of apoptosis-related genes, RNA was reverse-transcribed into cDNA by using the TransScript One-Step gDNA Removal and cDNA Synthesis SuperMix Kit (TransGen Biotech, China) following the manufacturer's instructions. Thereafter, qRT-PCR was performed in the LightCycler 480 system (Roche, Switzerland) with TransStart Green qPCR SuperMix (TransGen Biotech, China). U6 was selected as the reference gene. qRT-PCR conditions were set as follows: $95^{\circ} \mathrm{C}$ for $1 \mathrm{~min}$ followed by 40 cycles of $95^{\circ} \mathrm{C}$ for $20 \mathrm{~s}$ and $61^{\circ} \mathrm{C}$ for $31 \mathrm{~s}$. All primers were purchased from Sangon Biotech, China. 


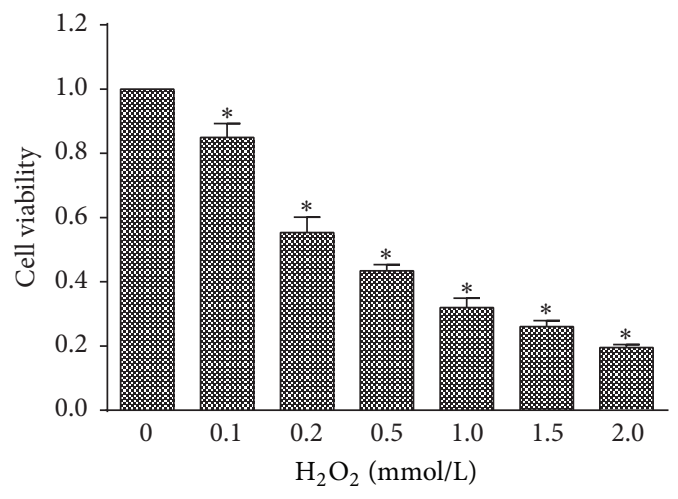

(a)

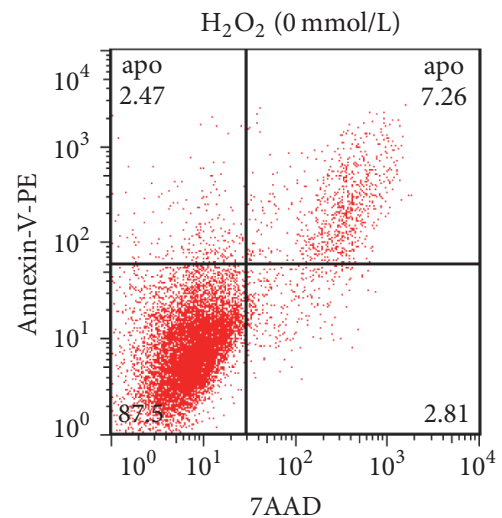

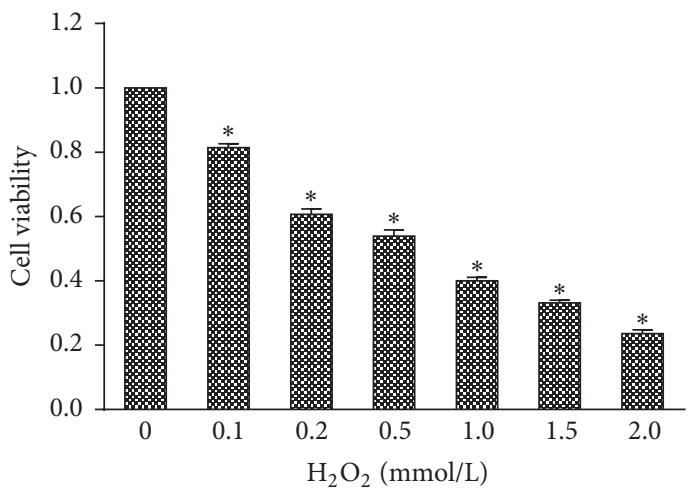

(b)
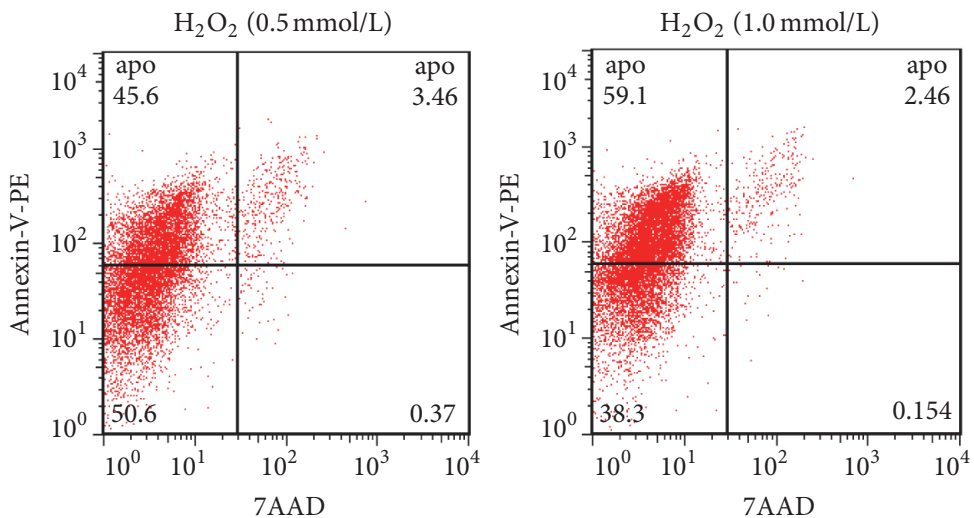

(c)

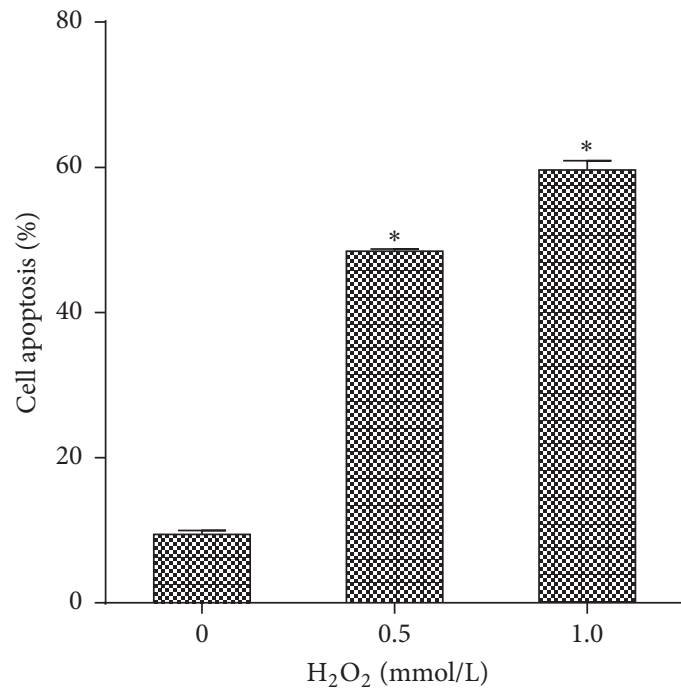

(d)

FIGURE 1: $\mathrm{H}_{2} \mathrm{O}_{2}$ induces cell death in a dose-dependent manner. (a) The effect of $\mathrm{H}_{2} \mathrm{O}_{2}$ on HUVECs viability compared to untreated control cells shown by the MTT assay. (b) Evaluation of HUVECs viability under $\mathrm{H}_{2} \mathrm{O}_{2}$ treatment using the ATP assay. (c) HUVECs were treated with $0,0.5$, or $1.0 \mathrm{mmol} / \mathrm{L} \mathrm{H}_{2} \mathrm{O}_{2}$ for $24 \mathrm{~h}$, and apoptosis was assessed by flow cytometry. (d) Flow cytometry analysis showed that $\mathrm{H}_{2} \mathrm{O}_{2}$ induced HUVEC apoptosis in a dose-dependent manner. All $n=3,{ }^{*} p<0.05$.

2.9. Western Blot. After $24 \mathrm{~h}$ of treatment with $\mathrm{H}_{2} \mathrm{O}_{2}(0$ or $0.5 \mathrm{mmol} / \mathrm{L}$ ), HUVECs were lysed using the radioimmunoprecipitation assay buffer with protease inhibitors, $1 \mathrm{mM}$ phenylmethylsulfonyl fluoride, and mercaptoethanol. The homogenate was centrifuged for $15 \mathrm{~min}$ at $4,500 \mathrm{rpm}$ at $4^{\circ} \mathrm{C}$, and the supernatant was used for sodium dodecyl sulfate polyacrylamide gel electrophoresis at $20 \mu \mathrm{g}$ of total protein per lane, followed by transfer to a polyvinylidene fluoride membrane. The membranes were blocked with nonfat dry milk for $90 \mathrm{~min}$ at room temperature and incubated with primary monoclonal rabbit anti-CASP8AP2 (1:200; Santa Cruz Biotechnology, USA), monoclonal rabbit anti-caspase-8 


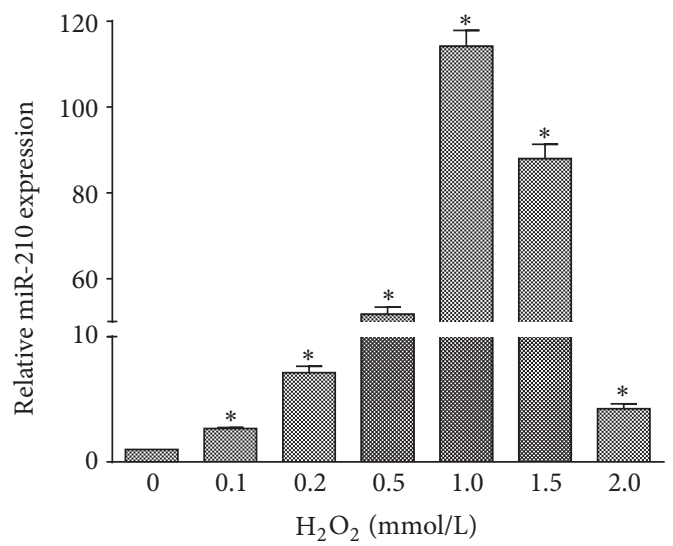

(a)

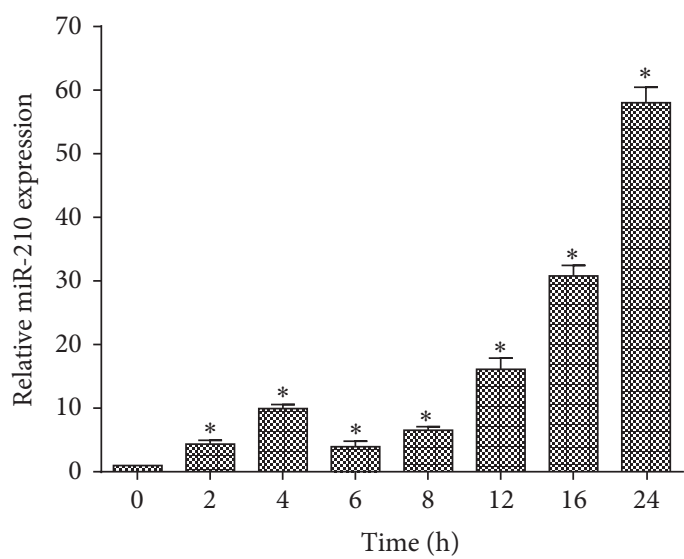

(b)

Figure 2: $\mathrm{H}_{2} \mathrm{O}_{2}$ increased miR-210 expression. (a) Incubation with $\mathrm{H}_{2} \mathrm{O}_{2}$ at different concentrations $(0.1,0.2,0.5,1.0,1.5$, and $2.0 \mathrm{mmol} / \mathrm{L})$ for $24 \mathrm{~h}$ increased miR-210 expression compared that in untreated control cells. miR-210 expression was highest at $1.0 \mathrm{mmol} / \mathrm{L}$. (b) HUVECs were treated with $\mathrm{H}_{2} \mathrm{O}_{2}$ at $0.5 \mathrm{mmol} / \mathrm{L}$ for $2,4,6,8,12,16$, and $24 \mathrm{~h}$. miR-210 expression increased in all cases compared to that in untreated control cells. All $n=3,{ }^{*} p<0.05$.

(1:1000; Cell Signaling Technology, USA), monoclonal rabbit anti-caspase-3 (1:1000; Cell Signaling Technology, USA), and monoclonal mouse anti- $\beta$-actin (1:2000; Proteintech, USA) antibodies, followed by incubation with a secondary horseradish peroxidase-conjugated anti-rabbit IgG antibody or anti-mouse IgG antibody (1:1000; Beyotime, China). The blots were visualized using the SuperSignal West Pico kit (Thermo Scientific, USA). The relative expression level of each protein was normalized to that of $\beta$-actin.

2.10. Statistical Analysis. Data are reported as means $\pm \mathrm{SE}$. Statistical analysis was performed using SPSS13.0 (IBM, USA). For all experiments, Student's $t$-test was employed to assess statistical significance, and the threshold was set at $p=0.05$.

\section{Results}

3.1. The Effect of $\mathrm{H}_{2} \mathrm{O}_{2}$ on Cell Viability and miR-210 Expression in HUVECs. HUVECs were treated with different concentrations of $\mathrm{H}_{2} \mathrm{O}_{2}(0,0.1,0.2,0.5,1.0,1.5$, and $2.0 \mathrm{mmol} / \mathrm{L})$, and cell viability was tested using the MTT assay and ATP assay. As shown in Figures 1(a) and 1(b), the viability of HUVECs was reduced with increasing $\mathrm{H}_{2} \mathrm{O}_{2}$ concentrations compared with that of control cells $(p<0.05)$. Apoptosis of HUVECs treated with different concentrations of $\mathrm{H}_{2} \mathrm{O}_{2}$ $(0,0.5$, and $1.0 \mathrm{mmol} / \mathrm{L})$ was evaluated by performing flow cytometry to determine whether $\mathrm{H}_{2} \mathrm{O}_{2}$-induced apoptosis contributed to cell viability variation (Figures $1(\mathrm{c})$ and $1(\mathrm{~d})$ ). The results demonstrated that $\mathrm{H}_{2} \mathrm{O}_{2}$ induced apoptosis in a dose-dependent manner $(p<0.05)$.

We then tested the expression of miR-210 in HUVECs with qPCR in response to stimulation with $\mathrm{H}_{2} \mathrm{O}_{2}$ at different concentrations $(0,0.1,0.2,0.5,1.0,1.5$, and $2.0 \mathrm{mmol} / \mathrm{L})$. miR-210 expression increased $(p<0.05$; Figure 2(a)), with the highest value observed at $1.0 \mathrm{mmol} / \mathrm{L}$. In addition, we investigated the dependence of miR-210 expression on duration of $\mathrm{H}_{2} \mathrm{O}_{2}$ stimulation. In HUVECs treated with $\mathrm{H}_{2} \mathrm{O}_{2}$ at $0.5 \mathrm{mmol} / \mathrm{L}$ for $0,2,4,6,8,16$, and $24 \mathrm{~h}$, miR-210 expression increased $(p<0.05$; Figure 2(b)). These results indicated that miR-210 was involved in HUVEC apoptosis induced by $\mathrm{H}_{2} \mathrm{O}_{2}$.

3.2. The Effect of miR-210 on HUVEC Apoptosis in Response to $\mathrm{H}_{2} \mathrm{O}_{2}$. Since miR-210 expression increased in HUVECs treated with $\mathrm{H}_{2} \mathrm{O}_{2}$, we tested the effect of miR-210 on HUVECs apoptosis upon $\mathrm{H}_{2} \mathrm{O}_{2}$ treatment using gain-andloss-of-function approaches. HUVECs were transduced with lentiviral vectors and observed under a fluorescence microscope (Figure 3(a)). The Image J software was used to quantitate the transduction efficiency (Figure 3(b)). The mean transduction efficiency of miR-Scr, pre-210, and anti-miR-210 was $0.88,0.89$, and 0.86 , respectively. qRT-PCR showed that miR-210 expression levels were increased in the pre-210 cell line and decreased in the anti-miR-210 cell line compared with that in normal HUVECs (all $p<0.05$ ). The level of miR-210 in the control cell line transfected with miR-Scr did not differ from that in normal HUVECs (Figure 3(b)). Moreover, during $\mathrm{H}_{2} \mathrm{O}_{2}$ stimulation ( $0.5 \mathrm{mmol} / \mathrm{L}, 24 \mathrm{~h}$ ), miR210 expression increased in the pre-210 cells and decreased in the anti-miR-210 cells compared with the miR-Scr cells (Figures 3(c) and 3(d)) (all $p<0.05)$.

We then investigated the effect of miR-210 on survival by treating HUVECs transduced with pre-210, anti-miR-210, and miR-Scr with $\mathrm{H}_{2} \mathrm{O}_{2}$ at different concentrations. The MTT assay showed that the cell viability ratio increased in pre210 HUVECs at all $\mathrm{H}_{2} \mathrm{O}_{2}$ concentrations and decreased in anti-miR-210 HUVECs treated with $\mathrm{H}_{2} \mathrm{O}_{2}$ at $0.2,0.5,1.0$, and $1.5 \mathrm{mmol} / \mathrm{L}$ compared with miR-Scr HUVECs (Figures 4(a) and 4(b)). Similar results were obtained with the ATP assay. Under $\mathrm{H}_{2} \mathrm{O}_{2}$ treatment, cell viability also increased in pre- 210 HUVECs at all concentrations and decreased in anti-miR210 HUVECs at $0.1,0.2,0.5$ and $1.0 \mathrm{mmol} / \mathrm{L}$ compared with miR-Scr HUVECs (Figures 4(c) and 4(d)). In agreement, flow 

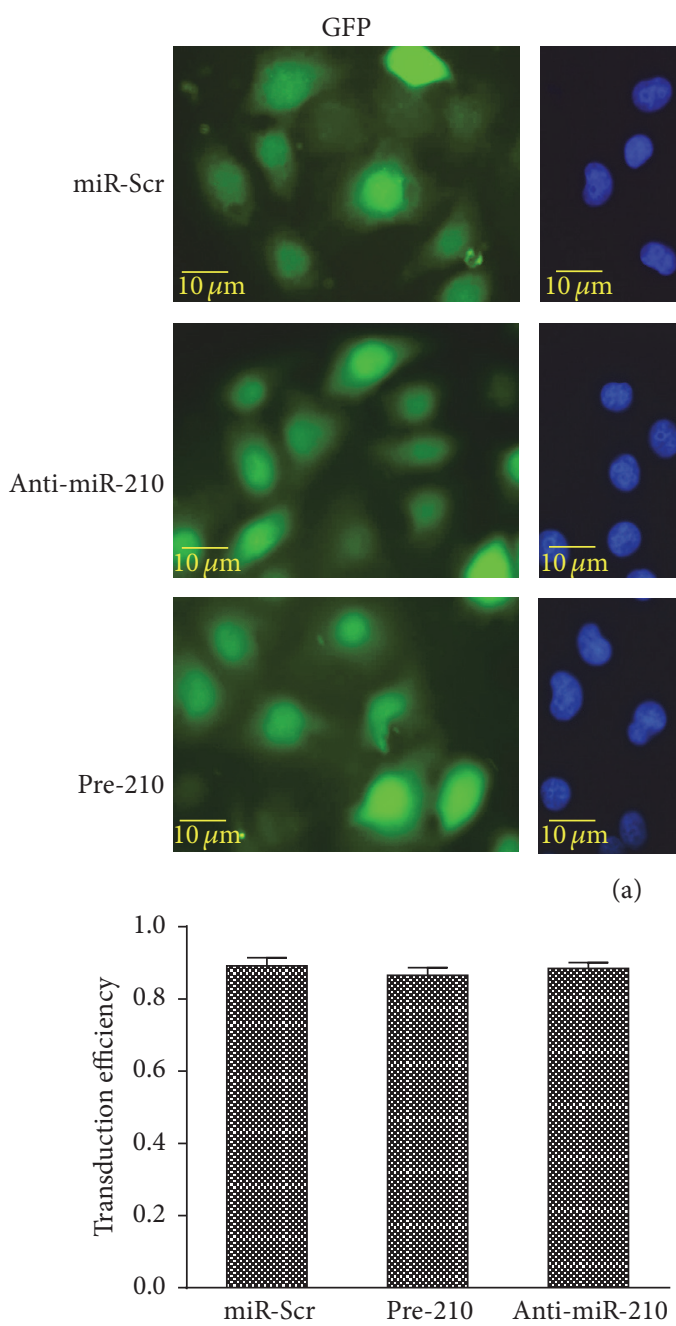

(b)

(a)
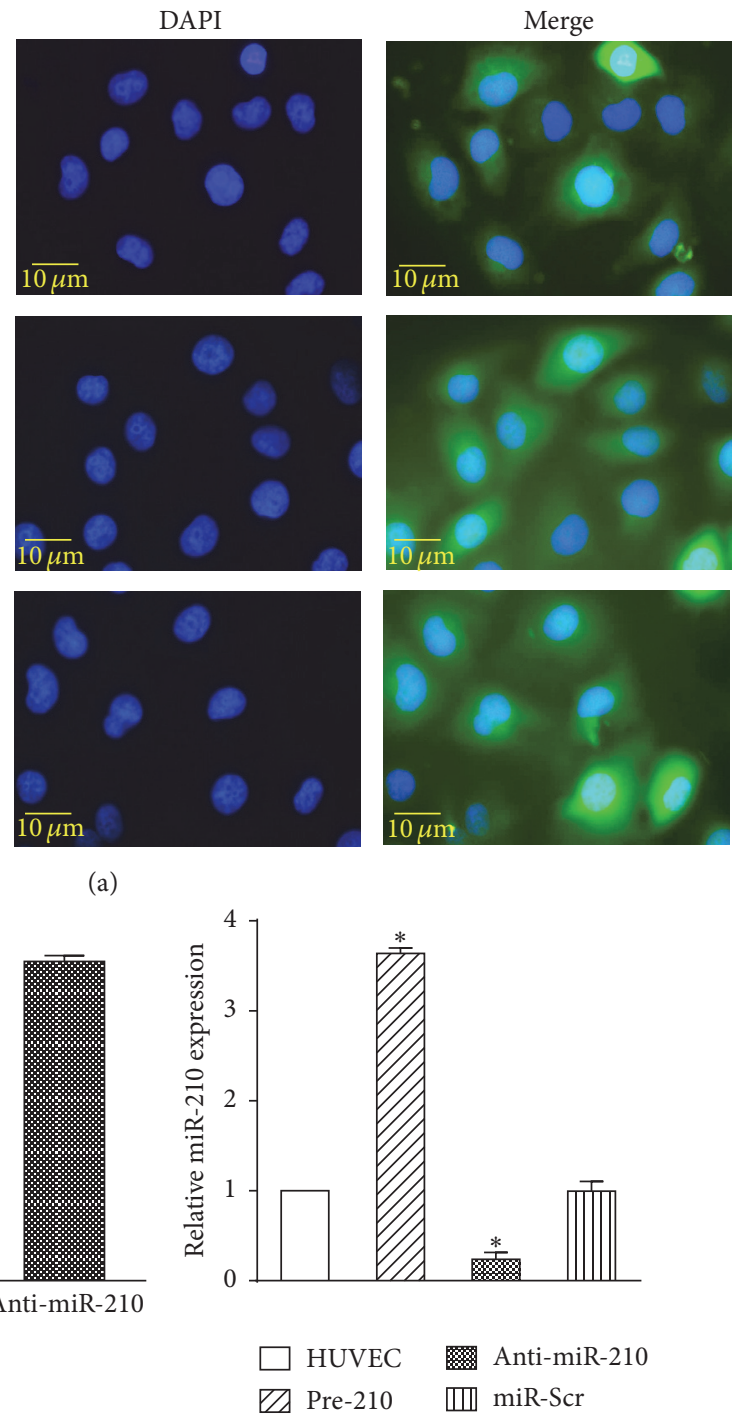

(c)

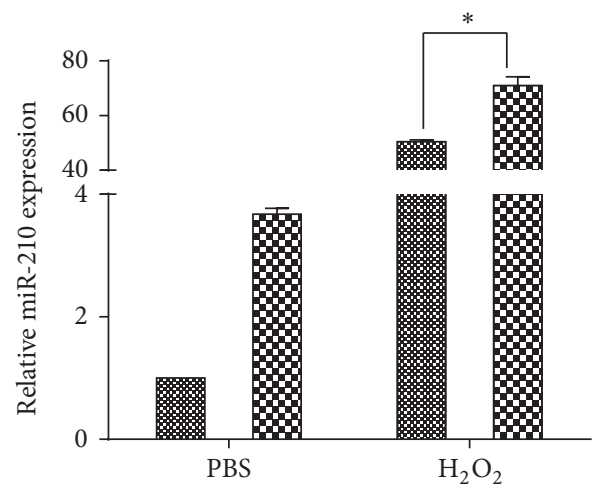

miR-Scr

8 Pre- 210

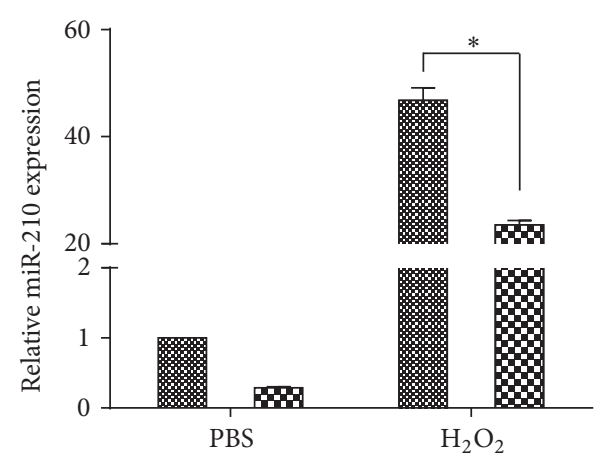

miR-Scr

8 Anti-miR-210

(e)

FIGURE 3: miR-210 expression variation in HUVECs transduced with lentivirus. (a) DAPI staining of HUVECs transduced with pre-210, anti-miR-210, and miR-Scr. (b) Quantification of transduction efficiency using the Image J software. (c) qRT-PCR results showing transgenic expression of miR-210 in HUVECs transduced with the lentivirus. (d) qRT-PCR results showing increased relative miR-210 expression in pre210 HUVECs compared with miR-Scr HUVECs upon $\mathrm{H}_{2} \mathrm{O}_{2}$ treatment. (e) qRT-PCR results showing decreased relative miR-210 expression in anti-miR-210 HUVECs compared with miR-Scr HUVECs upon $\mathrm{H}_{2} \mathrm{O}_{2}$ treatment. All $n=3,{ }^{*} p<0.05$. 

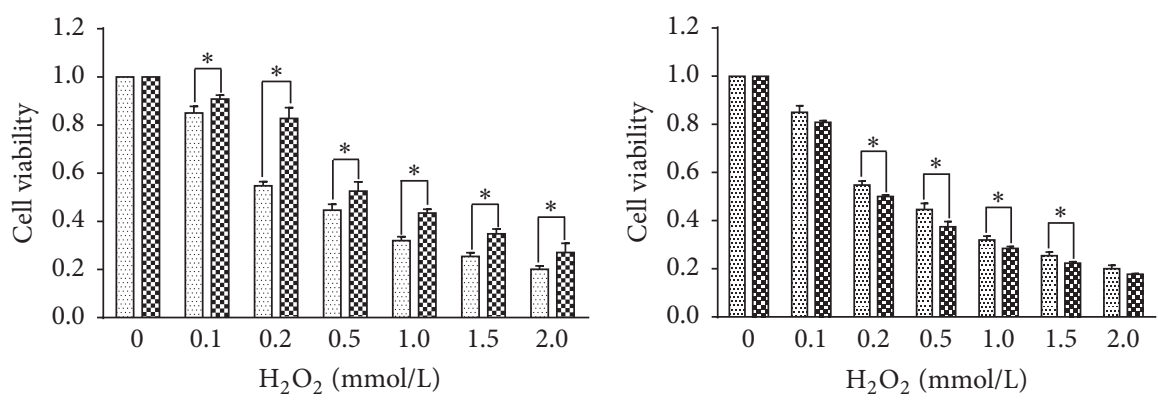

miR-Scr

miR-Scr

B) Pre-210

(8) Anti-miR-210

(a)

(b)
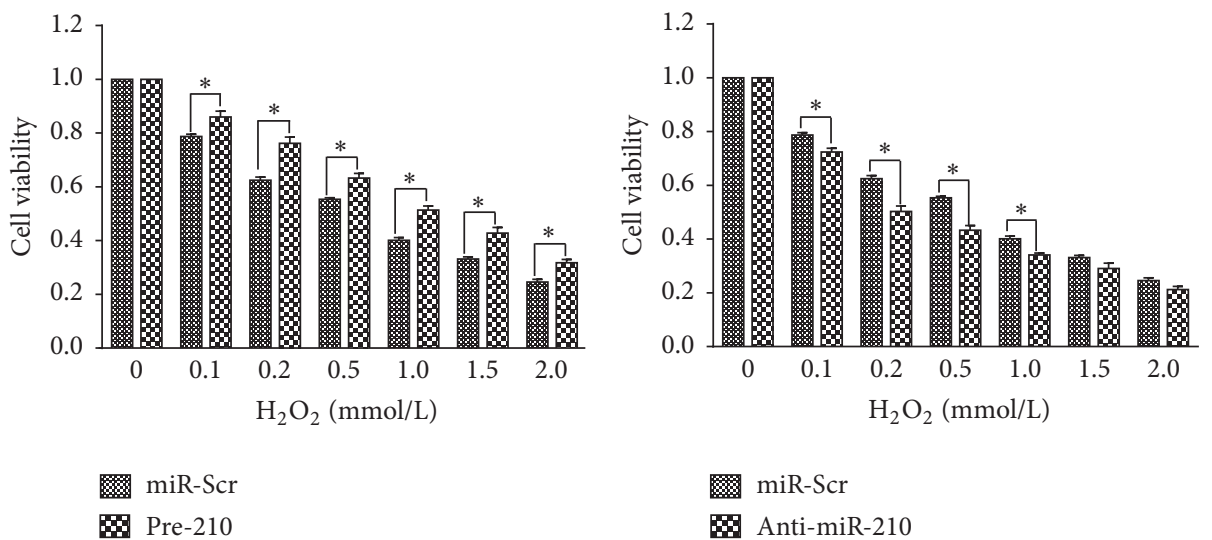

(c)

(d)
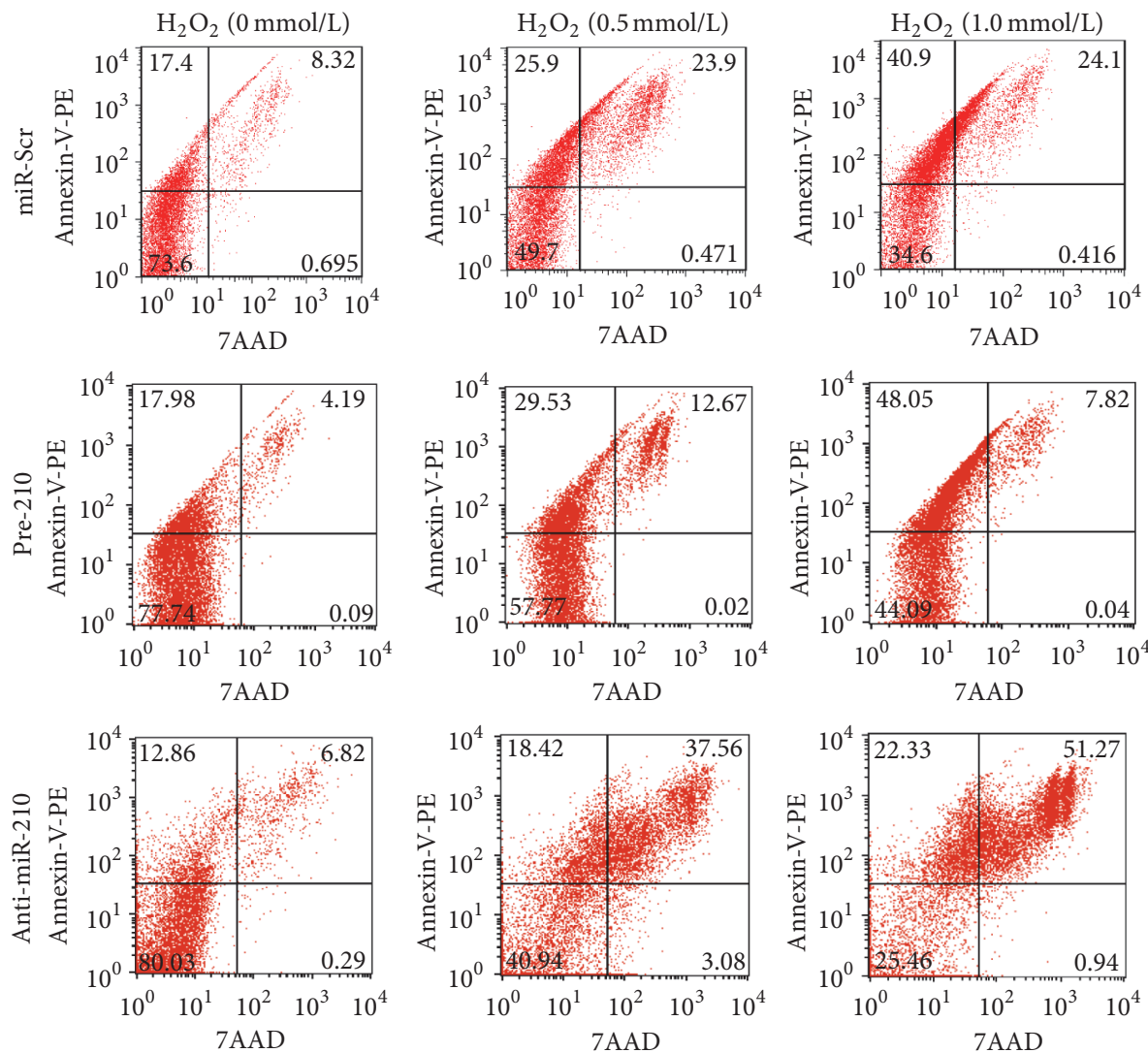

(e)

FIgURE 4: Continued. 


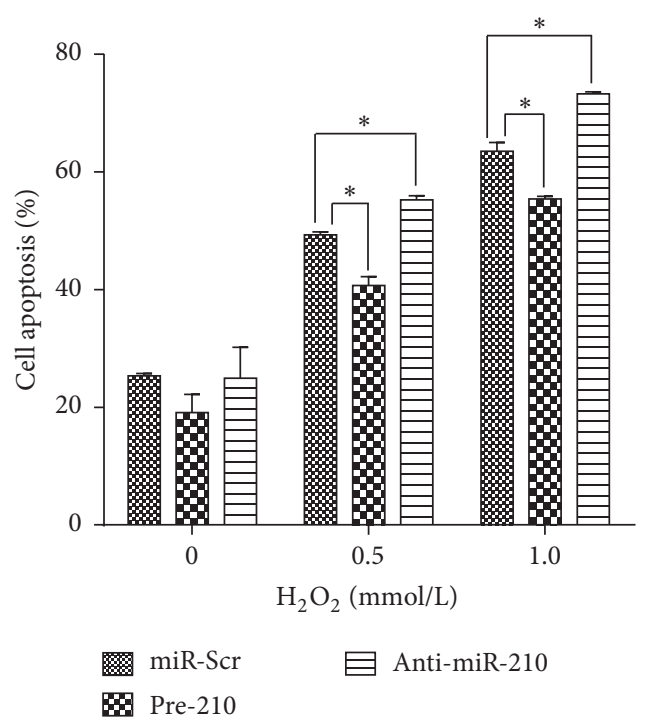

(f)

FIGURE 4: miR-210 reduced cell death in HUVECS treated with $\mathrm{H}_{2} \mathrm{O}_{2}$. (a) MTT assay results showing that miR-210 overexpression increased cell viability compared with that of miR-Scr HUVECs upon $\mathrm{H}_{2} \mathrm{O}_{2}$ treatment. (b) MTT assay results showing that miR-210 inhibition decreased cell viability compared with that of miR-Scr HUVECs upon $\mathrm{H}_{2} \mathrm{O}_{2}$ treatment. (c) ATP assay showing that miR-210 overexpression increased cell viability compared with that of miR-Scr HUVECs upon $\mathrm{H}_{2} \mathrm{O}_{2}$ treatment. (d) ATP assay showing that miR-210 inhibition decreased cell viability compared with that of miR-Scr HUVECs upon $\mathrm{H}_{2} \mathrm{O}_{2}$ treatment (e) Flow cytometry of the three transduced lines of HUVECs treated with $\mathrm{H}_{2} \mathrm{O}_{2}(0.5 \mathrm{mmol} / \mathrm{L}, 24 \mathrm{~h})$. (f) Flow cytometry analysis showing that miR-210 protected HUVECs from apoptosis during $\mathrm{H}_{2} \mathrm{O}_{2}$ treatment. All $n=3,{ }^{*} p<0.05$.

cytometry showed that the cell apoptosis ratio decreased in pre-miR-210 cells and increased in anti-miR-210 cells upon treating with $\mathrm{H}_{2} \mathrm{O}_{2}$ at 0.5 and $1.0 \mathrm{mmol} / \mathrm{L}(p<0.05$; Figures $4(\mathrm{c})$ and $4(\mathrm{~d}))$.

\subsection{The Effect of miR-210 on ROS Generation in HUVECs} in Response to $\mathrm{H}_{2} \mathrm{O}_{2}$. To investigate the effect of miR-210 on ROS generation, the cells were transfected with miR-210 mimics, miR-210 inhibitor, or NC, and ROS levels were determined after $\mathrm{H}_{2} \mathrm{O}_{2}$ treatment $(0,0.5 \mathrm{mmol} / \mathrm{L}, 24 \mathrm{~h})$. Based on the results of qPCR (see S1 Fig in Supplementary Material available online at https://doi.org/10.1155/2017/3565613), miR-210 expression increased after transfection with miR210 mimics and decreased after transfection with the miR210 inhibitor compared with that of untransfected HUVECs. No difference was found between untransfected HUVECs and those transfected with the NC. ROS levels (Figure 5) increased in the NC group and were higher in the miR210 inhibitor-transfected cells upon $\mathrm{H}_{2} \mathrm{O}_{2}$ treatment. Overexpression of miR-210 decreased the ROS levels during $\mathrm{H}_{2} \mathrm{O}_{2}$ treatment when compared with cells transfected with the NC.

3.4. $\mathrm{H}_{2} \mathrm{O}_{2}$ Effect on Relative Expression of Genes of the CASP8AP2 Pathway in HUVECs. Since the CASP8AP2 pathway plays an important role in apoptosis, we investigated its contribution to the $\mathrm{H}_{2} \mathrm{O}_{2}$-induced apoptosis in HUVECs. The miR-Scr cells were treated with $\mathrm{H}_{2} \mathrm{O}_{2}$ at 0 or $0.5 \mathrm{mmol} / \mathrm{L}$ for $24 \mathrm{~h}$, and expression of genes of the CASP8AP2 pathway was detected. There were no differences in mRNA expression after the $\mathrm{H}_{2} \mathrm{O}_{2}$ treatment (S2 Fig). However, Western blot results showed that, at protein level, CASP8AP2 expression increased after $\mathrm{H}_{2} \mathrm{O}_{2}$ treatment compared to the control $(p<0.05)$. In agreement, the cleaved caspase-8/caspase- 8 and cleaved caspase-3/caspase- 3 ratios were also increased (all $p<0.05$ ) (Figures 6(a)-6(c)). These results indicated that the CASP8AP2 pathway was involved in HUVEC apoptosis during $\mathrm{H}_{2} \mathrm{O}_{2}$ treatment.

\subsection{The Effect of miR-210 on the Expressions of CASP8AP2} Apoptosis Pathway-Related Genes in HUVECs Stimulated with $\mathrm{H}_{2} \mathrm{O}_{2}$. Since the CASP8AP2 pathway was involved in $\mathrm{H}_{2} \mathrm{O}_{2}$ mediated apoptosis, we investigated whether an association of the anti-apoptotic effect of miR-210 with CASP8AP2 pathway regulation existed. In HUVECs transduced with pre-210, anti-miR-210, and miR-Scr under $\mathrm{H}_{2} \mathrm{O}_{2}$ treatment ( 0 and $0.5 \mathrm{mmol} / \mathrm{L}, 24 \mathrm{~h}$ ), no differences were found in the mRNA expression of CASP8AP2, caspase-8, or caspase-3 (S2 Fig). Nevertheless, protein expression of these genes differed in the three cell lines. CASP8AP2 expression was decreased in the pre- 210 cells and increased in the anti-miR-210 cells compared with the miR-Scr cells (in cells both treated and not treated with $\mathrm{H}_{2} \mathrm{O}_{2}$, all $p<0.05$; Figures 6(a) and 6(d)). Without $\mathrm{H}_{2} \mathrm{O}_{2}$ treatment, there were no differences in the caspase8 cleavage or caspase- 3 cleavage in the pre-210, anti-miR-210, and miR-Scr cells. However, under $\mathrm{H}_{2} \mathrm{O}_{2}$ stimulation, both caspase- 8 cleavage and caspase- 3 cleavage decreased in the pre-210 cells and increased in the anti-miR-210 cells versus the miR-Scr cells (all $p<0.05$; Figures 6(b), 6(c), 6(e), and $6(\mathrm{f}))$. These results revealed that miR-210 downregulated the expression of CASP8AP2 pathway-related proteins. 

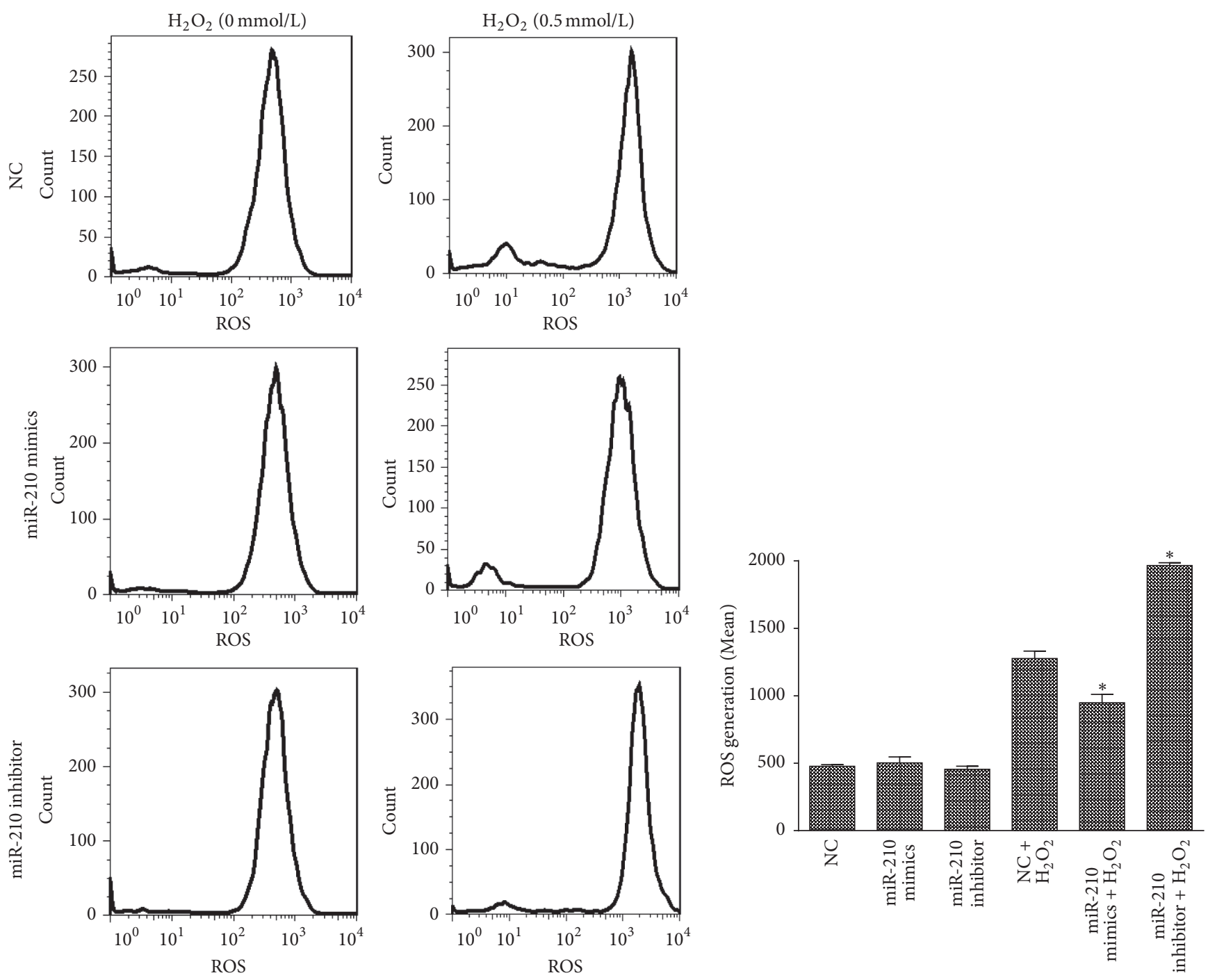

(a)

(b)

FIgURE 5: miR-210 reduced ROS generation in HUVECS treated with $\mathrm{H}_{2} \mathrm{O}_{2}$. (a) HUVECs were transfected with miR-210 mimics, miR-210 inhibitor, or $\mathrm{NC}$ and subsequently treated with $\mathrm{H}_{2} \mathrm{O}_{2}$ for $24 \mathrm{~h}(0,0.5 \mathrm{mmol} / \mathrm{L})$. Cells were collected and incubated with $10 \mu \mathrm{M}$ DCFH-DA for 20 minutes according to the manufacturer's instructions. After the incubation, the cells were washed with warm PBS, and ROS levels were analyzed by flow cytometry. (b) Quantification of mean fluorescent intensity in each group. Stars above bars refer to $p$ values between NC-transfected cells treated with $\mathrm{H}_{2} \mathrm{O}_{2}$ and the corresponding group. All $n=3,{ }^{*} p<0.05$.

\section{Discussion}

Endothelial cell apoptosis under oxidative stress plays a critical role in the initiation and progression of atherosclerosis [17]. In this study, we found that $\mathrm{H}_{2} \mathrm{O}_{2}$ induced HUVEC apoptosis through CASP8AP2 pathway activation. In addition, $\mathrm{H}_{2} \mathrm{O}_{2}$ stimulation upregulated the expression of miR-210, which protected HUVECs against $\mathrm{H}_{2} \mathrm{O}_{2}$-induced apoptosis by reducing ROS generation and affecting the CASP8AP2 pathway.

We found that $\mathrm{H}_{2} \mathrm{O}_{2}$ induced HUVEC apoptosis in a dose-dependent manner. In addition, CASP8AP2 pathwayrelated proteins were upregulated by the $\mathrm{H}_{2} \mathrm{O}_{2}$ treatment, which further contributed to the process of apoptosis. CASP8AP2 is a member of the apoptosis signaling complex that activates caspase- 8 , which results in the activation of caspase-3, eventually leading to apoptosis $[5,19]$. In agreement, our results showed that the CASP8AP2 protein expression level increased in miR-Scr HUVECs treated with $\mathrm{H}_{2} \mathrm{O}_{2}$. Furthermore, we found that the cleaved caspase8/caspase- 8 and cleaved caspase-3/caspase- 3 ratios increased, reflecting elevated activation of the initiator and effector caspases (caspase- 8 and caspase- 3 , resp.) that intensified apoptosis. Therefore, activation of the CASP8AP2 pathway leads to apoptosis in HUVECs under oxidative stress.

Moreover, miR-210 was upregulated in HUVECs during $\mathrm{H}_{2} \mathrm{O}_{2}$ stimulation. Some studies, including our previous work, showed that miR-210 upregulation had an antiapoptotic effect in the rat $\mathrm{H} 9 \mathrm{C} 2$ cell line [9], human mesenchymal stem cells [20], and mouse myoblast $\mathrm{C} 2 \mathrm{C} 12$ cell line [21]. 

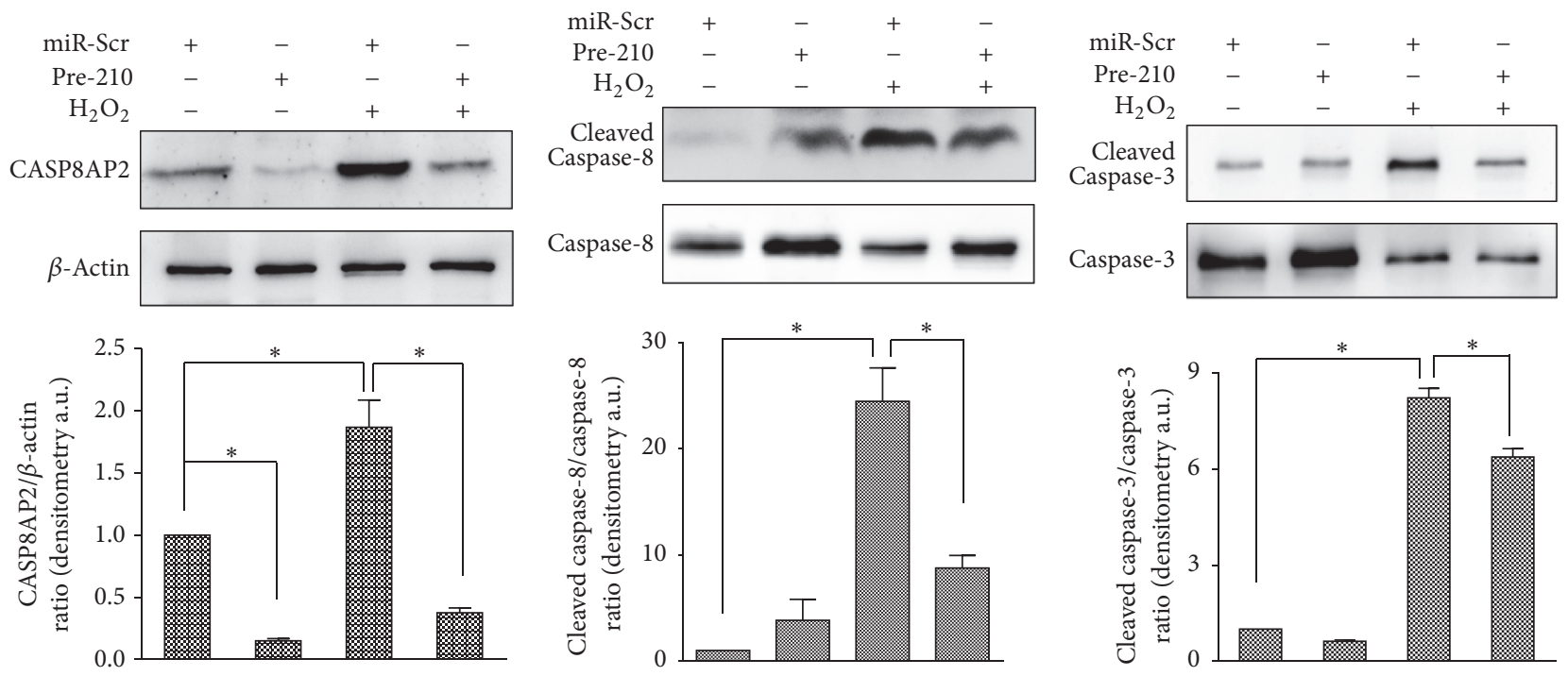

(a)

(b)
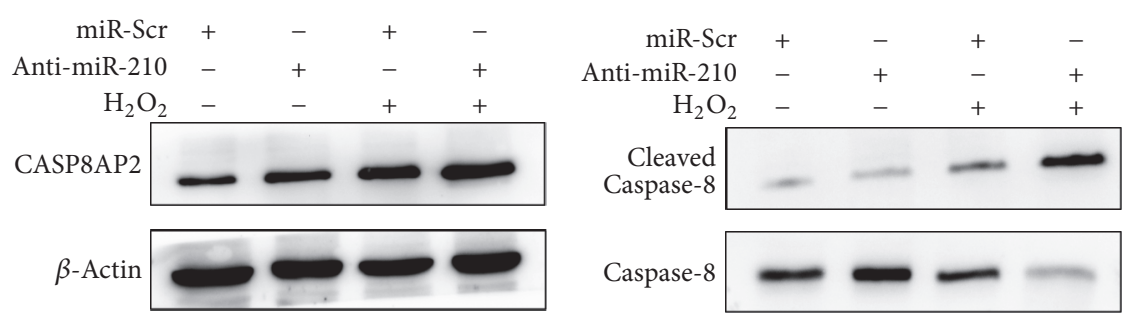

(c)

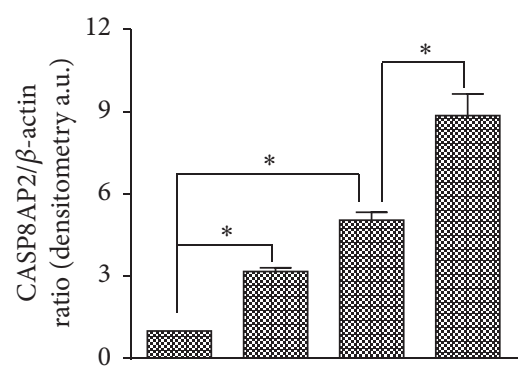

(d)

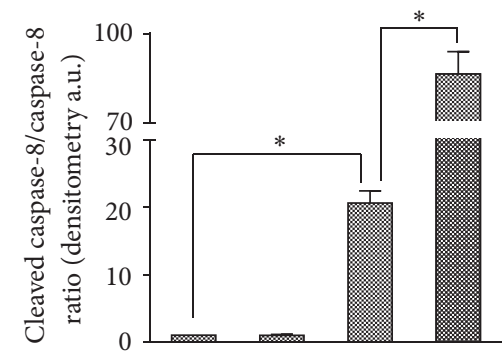

(e)

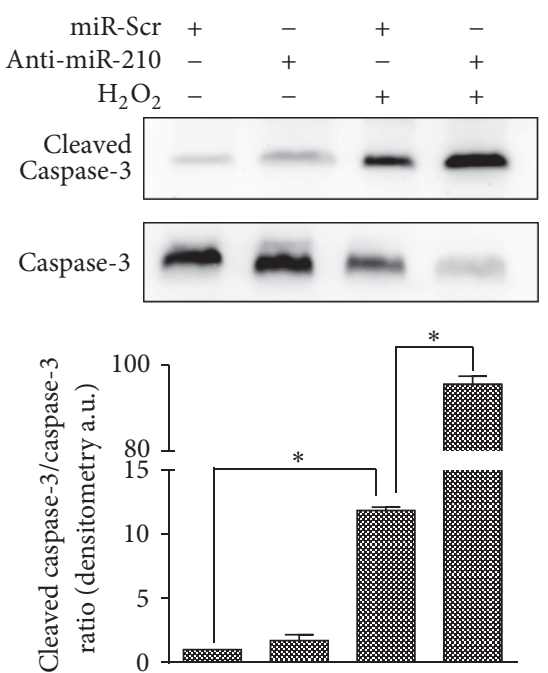

(f)

FIGURE 6: miR-210 downregulated CASP8AP2 pathway-related genes at the level of protein expression. (a) A Western blot showing that CASP8AP2 protein levels increased upon $\mathrm{H}_{2} \mathrm{O}_{2}$ treatment. miR-210 overexpression decreased the expression of CASP8AP2 in both $\mathrm{H}_{2} \mathrm{O}_{2}$ treated and untreated cells. (b) A Western blot showing that the cleaved caspase-8/caspase- 8 ratio increased upon $\mathrm{H}_{2} \mathrm{O}_{2}$ treatment. miR210 overexpression decreased the cleaved caspase-8/caspase- 8 ratio upon $\mathrm{H}_{2} \mathrm{O}_{2}$ treatment. (c) A Western blot showing that the cleaved caspase-3/caspase- 3 ratio increased upon $\mathrm{H}_{2} \mathrm{O}_{2}$ treatment. miR-210 overexpression decreased the cleaved caspase-3/caspase-3 ratio upon $\mathrm{H}_{2} \mathrm{O}_{2}$ treatment. (d) A Western blot showing that miR-210 inhibition increased CASP8AP2 protein levels in both the treated and untreated groups. (e) A Western blot showing that miR-210 inhibition increased the cleaved caspase-8/caspase- 8 ratio upon $\mathrm{H}_{2} \mathrm{O}_{2}$ treatment. (f) A Western blot showing that miR-210 inhibition increased the cleaved caspase-3/caspase- 3 ratio upon $\mathrm{H}_{2} \mathrm{O}_{2}$ treatment. All $n=3$, ${ }^{*} p<0.05$.

However, other studies showed that miR-210 had a proapoptotic effect in pulmonary artery epithelial cells [12], human lung cancer cell line [13], and esophageal cancer cell line [22]. Of interest, previous study demonstrated that miR-210 played different roles in HCT116 and MCF7 cells at different conditions [23]. In particular, miR-210 played a proapoptotic role at normal oxygen levels and an antiapoptotic role under hypoxia [23]. Our study found that miR-210 protected HUVECs against $\mathrm{H}_{2} \mathrm{O}_{2}$-induced apoptosis. In line with our results, Fasanaro et al. reported that miR-210 also had a prosurvival effect on HUVECs under hypoxia [6].
Furthermore, we found a negative correlation between miR-210 level and ROS generation upon $\mathrm{H}_{2} \mathrm{O}_{2}$ treatment. Increased ROS production is known to accelerate cell impairment. Our results indicated that miR-210 protected cells against apoptosis, which could be attributed to reduced ROS production under oxidative stress. Similar results were found in cardiomyocytes [4], mesenchymal stem cells [11], and ischemic hindlimbs [21]. However, contrasting results were obtained in colorectal cancer cells [24] and adipose-derived stem cells [25]. These differences could be due to the different cellular contexts. The underlying molecular mechanism of 
the reduced ROS generation could be related to the regulation of the c-Met pathway [11] and the expression of iron-sulfur cluster scaffold homolog [23].

We found that the antiapoptotic effect of miR-210 was also associated with the CASP8AP2 pathway. Overexpression of miR-210 inhibited the protein expression level of CASP8AP2 and thus decreased the cleaved caspase-8/caspase- 8 ratio during $\mathrm{H}_{2} \mathrm{O}_{2}$ treatment, while miR-210 inhibition led to the opposite effect. These results suggested that miR-210 downregulated the CASP8AP2 pathway under oxidative stress.

Although CASP8AP2 was identified as a target of miR210 in bone marrow-derived mesenchymal stem cells under anoxia [5], Barile et al. found no association between miR-210 and CASP8AP2 in HL-1 cells [26], which indicates that the target genes of miR-210 may vary with different cell types and conditions. Moreover, numerous studies identified several other target genes of miR-210, including Efna3 [27], neuronal pentraxin 1 [28], E2f3 [29], PTPN2 [30], and ptplb [10], suggesting that miR-210 has diverse roles in angiogenesis, DNA repair, cell cycle, migration, and apoptosis. Further studies on the association between miR-210 and other potential target genes in HUVECs under oxidative stress need to be conducted.

Of note, we found no differences in mRNA expression of CASP8AP2, caspase-8, and caspase- 3 during $\mathrm{H}_{2} \mathrm{O}_{2}$ treatment versus control cells. It is possible that alterations in mRNA expression occurred prior to the changes in protein levels. Our results indicate that miR-210 protects HUVECs against oxidative stress in in vitro models. However, further research is needed to investigate the role of miR-210 in in vivo models and determine the underlying mechanisms.

\section{Conclusions}

We observed that miR-210 expression increased in HUVECs treated with $\mathrm{H}_{2} \mathrm{O}_{2}$. Moreover, miR-210 played a prosurvival and antiapoptotic role in HUVECs under oxidative stress by reducing ROS generation and downregulating the CASP8AP2 pathway. However, apoptosis-related pathways other than the CASP8AP2 pathway are known to exist. Further research on the relationship between miR-210 and these pathways is warranted. Our result may potentially lead to a new strategy for protecting against endothelial injury in atherosclerosis.

\section{Competing Interests}

The authors declare that there is no conflict of interests regarding the publication of this paper.

\section{Acknowledgments}

This study was supported by grants from the National Natural Science Foundation of China (no. 81570250), Jilin Province Department of Finance, China (no. 2014520), and the National Clinical Key Specialty Project.

\section{References}

[1] D. Mozaffarian, E. J. Benjamin, A. S. Go et al., "Executive summary: heart disease and stroke statistics-2016 update: a report from the American Heart Association," Circulation, vol. 133, no. 4, pp. 447-454, 2016.

[2] L. Ma, X. Guo, and W. Chen, "Inhibitory effects of oleoylethanolamide (OEA) on $\mathrm{H}_{2} \mathrm{O}_{2}$-induced human umbilical vein endothelial cell (HUVEC) injury and apolipoprotein $\mathrm{E}$ knockout (ApoE-/-) atherosclerotic mice," International Journal of Clinical and Experimental Pathology, vol. 8, no. 6, pp. 6301-6311, 2015.

[3] D. Gou, R. Ramchandran, X. Peng et al., "miR-210 has an antiapoptotic effect in pulmonary artery smooth muscle cells during hypoxia," AJP: Lung Cellular and Molecular Physiology, vol. 303, no. 8, pp. L682-L691, 2012.

[4] R. K. Mutharasan, V. Nagpal, Y. Ichikawa, and H. Ardehali, "microRNA-210 is upregulated in hypoxic cardiomyocytes through Akt- and p53-dependent pathways and exerts cytoprotective effects," American Journal of Physiology-Heart and Circulatory Physiology, vol. 301, no. 4, pp. H1519-H1530, 2011.

[5] H. W. Kim, H. K. Haider, S. Jiang, and M. Ashraf, "Ischemic preconditioning augments survival of stem cells via miR-210 expression by targeting caspase-8-associated protein 2," Journal of Biological Chemistry, vol. 284, no. 48, pp. 33161-33168, 2009.

[6] P. Fasanaro, Y. D’Alessandra, V. Di Stefano et al., "MicroRNA210 modulates endothelial cell response to hypoxia and inhibits the receptor tyrosine kinase ligand ephrin-A3," Journal of Biological Chemistry, vol. 283, no. 23, pp. 15878-15883, 2008.

[7] H. W. Kim, S. Jiang, M. Ashraf, and K. H. Haider, "Stem cell-based delivery of Hypoxamir-210 to the infarcted heart: implications on stem cell survival and preservation of infarcted heart function," Journal of Molecular Medicine, vol. 90, no. 9, pp. 997-1010, 2012.

[8] Z. Zhang, H. Sun, H. Dai et al., "MicroRNA miR-210 modulates cellular response to hypoxia through the MYC antagonist MNT," Cell Cycle, vol. 8, no. 17, pp. 2756-2768, 2009.

[9] Y.-F. Shi, N. Liu, Y.-X. Li et al., "Insulin protects H9c2 rat cardiomyoblast cells against hydrogen peroxide-induced injury through upregulation of microRNA-210," Free Radical Research, vol. 49, no. 9, pp. 1147-1155, 2015.

[10] S. Hu, M. Huang, Z. Li et al., "MicroRNA-210 as a novel therapy for treatment of ischemic heart disease," Circulation, vol. 122, no. 11, pp. S124-S131, 2010.

[11] J. Xu, Z. Huang, L. Lin et al., "miR-210 over-expression enhances mesenchymal stem cell survival in an oxidative stress environment through antioxidation and c-Met pathway activation," Science China Life Sciences, vol. 57, no. 10, pp. 989-997, 2014.

[12] S. Y. Chan, Y.-Y. Zhang, C. Hemann, C. E. Mahoney, J. L. Zweier, and J. Loscalzo, "MicroRNA-210 controls mitochondrial metabolism during hypoxia by repressing the iron-sulfur cluster assembly proteins ISCU1/2," Cell Metabolism, vol. 10, no. 4, pp. 273-284, 2009.

[13] M.-P. Puisségur, N. M. Mazure, T. Bertero et al., "MiR-210 is overexpressed in late stages of lung cancer and mediates mitochondrial alterations associated with modulation of HIF-1 activity," Cell Death \& Differentiation, vol. 18, no. 3, pp. 465-478, 2011.

[14] A. Vennemann and T. G. Hofmann, "SUMO regulates proteasome-dependent degradation of FLASH/Casp8AP2," Cell Cycle, vol. 12, no. 12, pp. 1914-1921, 2013. 
[15] X.-C. Yang, B. D. Burch, Y. Yan, W. F. Marzluff, and Z. Dominski, "FLASH, a Proapoptotic Protein Involved in Activation of Caspase-8, Is Essential for 3/ End Processing of Histone PremRNAs," Molecular Cell, vol. 36, no. 2, pp. 267-278, 2009.

[16] K. Milovic-Holm, E. Krieghoff, K. Jensen, H. Will, and T. G. Hofmann, "FLASH links the CD95 signaling pathway to the cell nucleus and nuclear bodies," EMBO Journal, vol. 26, no. 2, pp. 391-401, 2007.

[17] S. Liu, R. Luo, Q. Xiang, X. Xu, L. Qiu, and J. Pang, "Design and synthesis of novel xyloketal derivatives and their protective activities against $\mathrm{H}_{2} \mathrm{O}_{2}$-induced huvec injury," Marine Drugs, vol. 13, no. 2, pp. 948-973, 2015.

[18] Y. Duan, S. Liu, J. Tao et al., "Cellular repressor of E1A stimulated genes enhances endothelial monolayer integrity," Molecular Biology Reports, vol. 40, no. 6, pp. 3891-3900, 2013.

[19] Y. Imai, T. Kimura, A. Murakami, N. Yajima, K. Sakamaki, and S. Yonehara, "The CED-4-homologous protein FLASH is involved in Fas-mediated activation of caspase-8 during apoptosis," Nature, vol. 398, pp. 777-785, 1999.

[20] W. Chang, C. Y. Lee, J.-H. Park et al., "Survival of hypoxic human mesenchymal stem cells is enhanced by a positive feedback loop involving mir-210 and hypoxia-inducible factor 1," Journal of Veterinary Science, vol. 14, no. 1, pp. 69-76, 2013.

[21] G. Zaccagnini, B. Maimone, V. Di Stefano et al., "Hypoxiainduced miR-210 modulates tissue response to acute peripheral ischemia," Antioxidants and Redox Signaling, vol. 21, no. 8, pp. 1177-1188, 2014.

[22] S. Tsuchiya, T. Fujiwara, F. Sato et al., "MicroRNA-210 regulates cancer cell proliferation through targeting fibroblast growth factor receptor-like 1(FGFRL1)," Journal of Biological Chemistry, vol. 286, no. 1, pp. 420-428, 2011.

[23] E. Favaro, A. Ramachandran, R. McCormick et al., "MicroRNA210 regulates mitochondrial free radical response to hypoxia and krebs cycle in cancer cells by targeting iron sulfur cluster protein ISCU," PLOS ONE, vol. 5, no. 4, Article ID e10345, 2010.

[24] K. E. Tagscherer, A. Fassl, T. Sinkovic et al., "MicroRNA-210 induces apoptosis in colorectal cancer via induction of reactive oxygen," Cancer Cell International, vol. 16, no. 1, article 42, 2016.

[25] S. Kang, S.-M. Kim, and J.-H. Sung, "Cellular and molecular stimulation of adipose-derived stem cells under hypoxia," Cell Biology International, vol. 38, no. 5, pp. 553-562, 2014.

[26] L. Barile, V. Lionetti, E. Cervio et al., "Extracellular vesicles from human cardiac progenitor cells inhibit cardiomyocyte apoptosis and improve cardiac function after myocardial infarction," Cardiovascular Research, vol. 103, no. 4, pp. 530-541, 2014.

[27] S. Ujigo, N. Kamei, H. Hadoush et al., "Administration of microRNA-210 promotes spinal cord regeneration in mice," Spine, vol. 39, no. 14, pp. 1099-1107, 2014.

[28] K. Pulkkinen, T. Malm, M. Turunen, J. Koistinaho, and S. YläHerttuala, "Hypoxia induces microRNA miR-210 in vitro and in vivo," FEBS Letters, vol. 582, no. 16, pp. 2397-2401, 2008.

[29] A. Giannakakis, R. Sandaltzopoulos, J. Greshock et al., "miR-210 links hypoxia with cell cycle regulation and is deleted in human epithelial ovarian cancer," Cancer Biology and Therapy, vol. 7, no. 2, pp. 255-264, 2008.

[30] J. H. Kim, S. G. Park, S.-Y. Song, J. K. Kim, and J.-H. Sung, "Reactive oxygen species-responsive miR-210 regulates proliferation and migration of adipose-derived stem cells via PTPN2," Cell Death and Disease, vol. 4, 2013. 


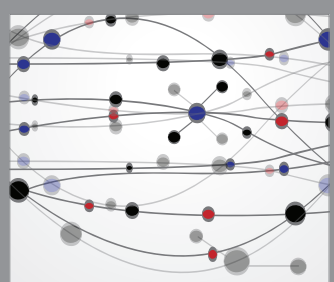

The Scientific World Journal
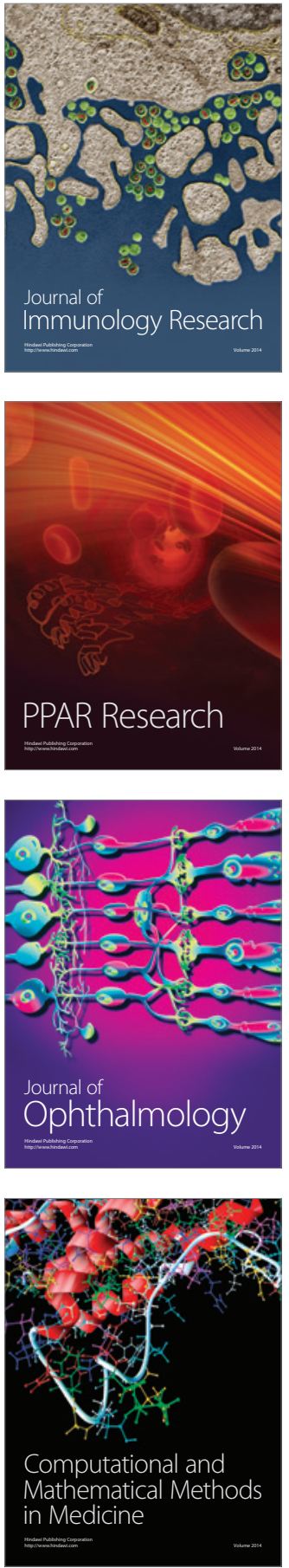

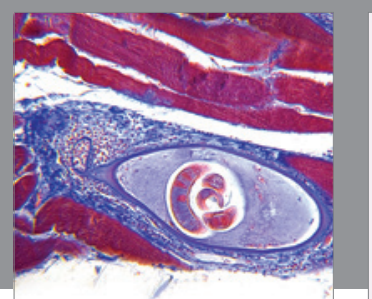

Gastroenterology Research and Practice
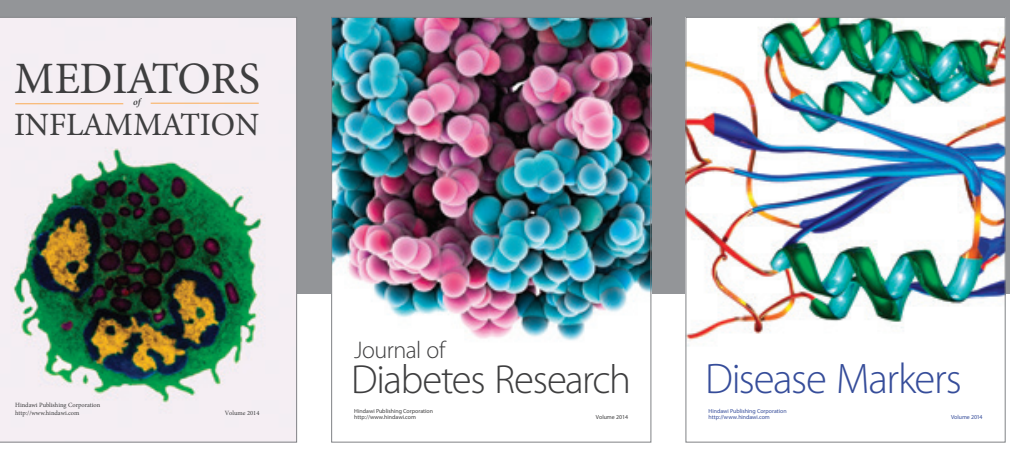

Disease Markers

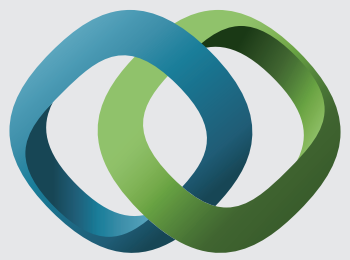

\section{Hindawi}

Submit your manuscripts at

https://www.hindawi.com
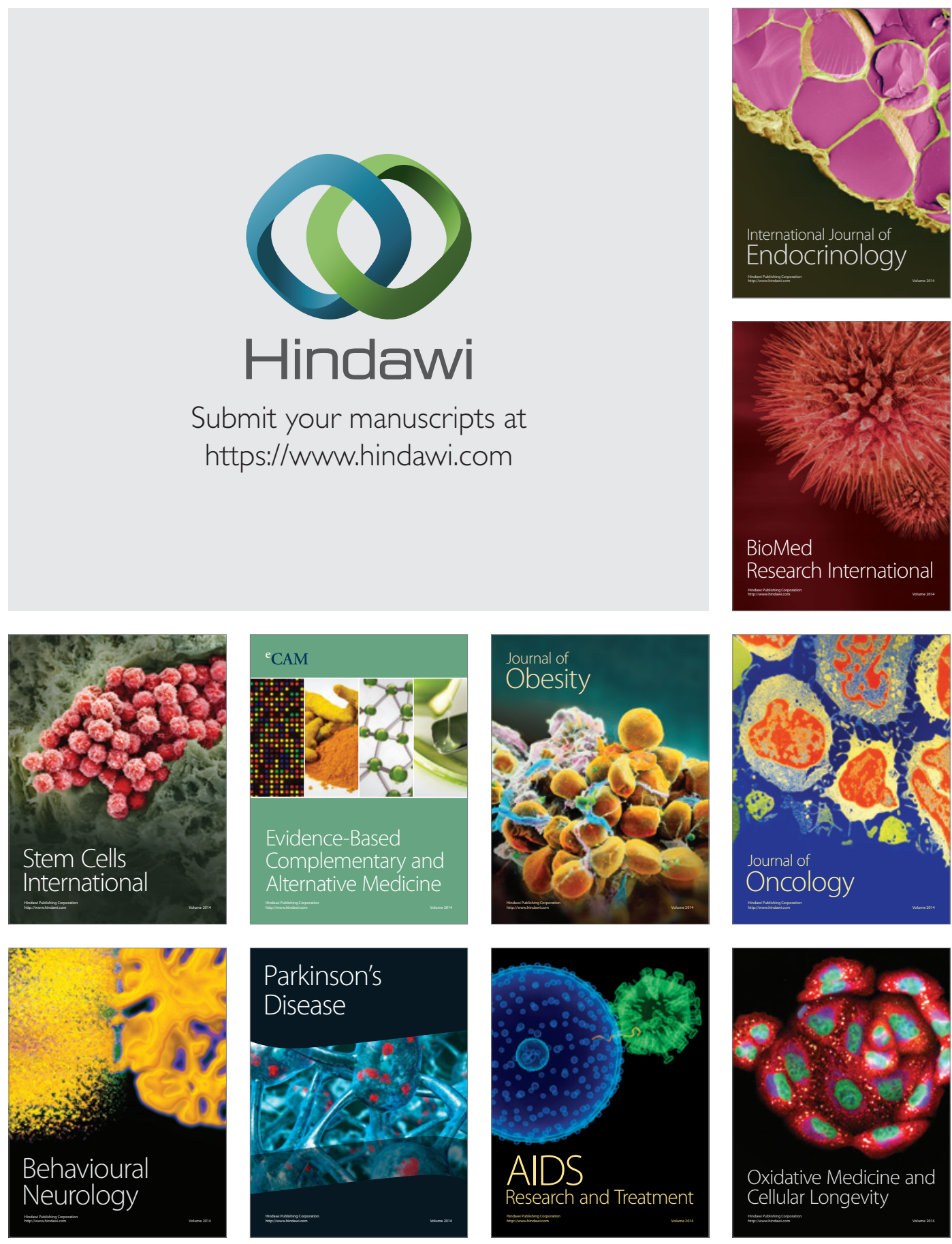